\title{
Suppression of ribosomal protein synthesis and protein translation factors by Peg-interferon alpha/ribavirin in HCV patients blood mononuclear cells (PBMC)
}

Rahul Gupta', Sun $\mathrm{Kim}^{3}$ and Milton W Taylor ${ }^{2^{*}}$

\begin{abstract}
Background: We have previously reported the induction of many interferon stimulated genes (ISGs) in PBMC collected from patients infected with HCV at various times after initiation of interferon-ribavirin treatment using DNA microarrays to identify changes in gene expression with time. Almost as many genes are down regulated (suppressed) during interferon-ribavirin treatment as are up regulated.
\end{abstract}

Methods: DNA microarrays were analyzed by different software, including MAS5 (Affymetrix-Kegg) and GSEA (gene set enrichment analysis) to identify specific pathways both up regulated and down regulated. Data was assessed from a clinical trial, which was a microarray analysis from 68 patients.

Results: Up regulated genes included genes associated with NF-kb, toll like receptor cytokine -cytokine interaction, and complement and adhesion pathways. The most prominent pathway down regulated was that for ribosomal structural proteins, and eukaryotic translational factors. Down regulation of ribosomal protein genes continued through the treatment up to the last measurement, which was at day 28.

Conclusions: This suppression of the protein synthetic apparatus might explain the long-term side effects of interferon-ribavirin, and explain a non-specific effect of interferon-ribavirin on viral protein synthesis. There was no evidence for unique transcription factors or micro RNA involvement.

Keywords: Ribosomal proteins, Transcription factors, Interferon, Ribavirin, Hepatitis C

\section{Introduction}

Hepatitis C virus (HCV) infection is a significant global public health problem, affecting approximately 150 million individuals worldwide and over 4 million in the United States alone, where it is the predominant blood-borne infection [1]. It is currently the leading indication for a liver transplant and is responsible for 8,000-10,000 deaths annually. Treatment with Interferon $-\alpha$ has formed the backbone of therapy against $\mathrm{HCV}$, first as mono-therapy, then in combination with the nucleoside analogue ribavirin. Current standard of care for chronic HCV infection consists of a regimen of pegylated interferon in combination with ribavirin and more recently the addition of a

\footnotetext{
* Correspondence: taymil@indiana.edu

${ }^{2}$ Department of Biology, Indiana University, Bloomington, IN, USA Full list of author information is available at the end of the article
}

protease inhibitor [2]. The combination of pegylated IFNalpha and ribavirin successfully eradicates the virus from $50-60 \%$ of those treated depending on antigenic strain of the virus and race of the patient. Genotype $1 \mathrm{a}$ and $1 \mathrm{~b}$ the most prevalent genotypes in the USA are the most difficult to eradicate, and the sustained response rate among African Americans is lower than that found in other racial groups [3].

Conventional analysis of DNA microarrays between control (before treatment) and interferon treated samples results in large lists of genes induced or down regulated that in many cases appear to be unconnected $[4,5]$. In the typical experiment one looks for fold increases in expression of specific genes, using paired Student's $t$-test to assess significance between the different treatments (or classes). We have reported that approximately 1,000 
genes are modified in gene expression in RNA isolated from PBMC of hepatitis $C$ patients being treated with Pegasys/ribavirin [5] using a 1.5 fold cut off and a p value of $<0.001$. Utilizing a mathematical approach in which we compared clustering of patient response with gene expression we have identified 36 genes that appear to be closely correlated with the antiviral response [6] An alternative method of analyzing microarrays, called gene set enrichment analysis (GSEA) has been published. This approach utilizes our knowledge of specific pathways, chromosomal location, presence of common DNA sequences and different transcription binding sites, and instead of giving each gene a statistical value it determines whether members of a gene set $S$ tend to occur toward the top (or bottom) of the list $L$, which will correlate with phenotype. This approach has been successfully used in analyzing data from muscle biopsies from diabetics vs. healthy controls [7]. The method revealed that genes involved in oxidative phosphorylation (OXPHOS) show reduced expression in diabetics, although the average decrease per gene is only $20 \%$. Thus this method can identify pathways that may be important, since a $20 \%$ increase or decrease in specific metabolic pathways may affect the outcome of many disease situations and might not be detected by the software used to analyze microarrays, which usually is set at a two-fold increase or decrease and a $p$ value of $<0.001$. In our previous work we have emphasized as have others the role of gene induced following interferon/ribavirin treatment but ignored genes suppressed or down regulated

In this paper we present a reanalysis of data from a large clinical trials, Virahep C, in which DNA microarrays were performed on PBMC from 68 patients receiving a regimen of interferon-alpha 2a (Pegasys)/ribavirin. In particular we noted the suppression of gene transcription in the ribosomal proteins-eukaryotic translation and elongation factor pathways.

\section{Materials and methods}

\section{Patient treatment and samples}

The patient samples used in this study have previously been described [5]. Approval was received from the Indiana University Human Subjects Committee.

\section{RNA extraction}

Peripheral Blood Mononuclear Cell (PBMC) Preparation and RNA extraction were as previously described $[5,8,9]$.

\section{RNA labeling and hybridization}

Preparation of cDNA, cRNA, and labeling were carried out according to the protocols recommended by Affymetrix in the GeneChip ${ }^{\circledR}$ Expression Analysis Technical Manual (Affymetrix, Santa Clara, CA), as previously described [9].

\section{Array analysis and data processing}

The Human Genome U133A microarray containing 22,000 genes was used. The microarrays were scanned using a dedicated Model 3000 scanner, controlled by Affymetrix Microarray Suite 5 software (MAS5). Global scaling to a target intensity of 1,000 normalized the average intensity on each array. Data were exported from MAS5 into a custom-designed database (MicroArray Data Portal) at the Center for Medical Genomics (IUPUI, Indianapolis). For GSEA analysis no filters were applied to the gene sets, thus all 22,000 genes at each time point were used for this analysis

\section{GSEA analysis}

We used the GSEA software [10] to identify pathways that appeared to be over expressed in one or other of our phenotypic classes. GSEA evaluates a query microarray dataset using a collection of gene sets. The $Q$ value for determining significance was an FDR of $<0.25$

\section{Results}

We have previously reported that the transcription of a large number of genes is induced or increased above background in PBMC harvested from patients with hepatitis $C$ during the course of treatment with pegylatedInterferon-alpha (Pegasys) and ribavirin $[5,8]$ Although the transcription of an equal number of genes is downregulated we have not previously attempted to classify them by pathway analysis. We have reanalyzed this data using alternative methods of analysis including GSEA [10], and other methods that classify genes by pathways rather than as individual genes. The results of GSEA analysis are presented in Table 1 using a False Detection Rate (FDR) calculation of $<0.025$ for both pathways up regulated and down regulated, using the latest Kegg and Reactome classification. The number of pathways induced declines by day 7 reflecting the return to near normal levels of gene transcription within a week of initiating treatment and the transient nature of much of the interferon response [8]. Day 28 was the last day in which data was available. The major pathways induced are DNA sensing pathways and the RIG-I like receptor signaling pathway reflecting binding of dsRNA to toll -like receptors. The only pathway down regulated at the level of FDR, 0.25 in this group of patients following treatment is the ribosomal pathway including ribosomal proteins initiation factors and elongation factors required for protein synthesis. The down regulated genes and fold difference following treatment at day 1 and 2 are presented in Table 2 and Table 3.

Figure 1(a-e) present heat map of the ribosomal proteins and other genes related to translation of proteins at the various times during treatment compared to before treatment. 
Table 1 PBMC treated with IFN/ribavirin. (Continued)

\begin{tabular}{|c|c|c|}
\hline KEGG_PROTEASOME & 41 & 0.02 \\
\hline KEGG_TOLL_LIKE_RECEPTOR_SIGNALING_PATHWAY & 70 & 0.02 \\
\hline KEGG_LYSOSOME & 88 & 0.04 \\
\hline KEGG_TRYPTOPHAN_METABOLISM & 17 & 0.04 \\
\hline KEGG_COMPLEMENT_AND_COAGULATION_CASCADES & 21 & 0.06 \\
\hline KEGG_CITRATE_CYCLE_TCA_CYCLE & 25 & 0.09 \\
\hline KEGG_CHEMOKINE_SIGNALING_PATHWAY & 104 & 0.15 \\
\hline KEGG_LEISHMANIA_INFECTION & 51 & 0.15 \\
\hline KEGG_SNARE_INTERACTIONS_IN_VESICULAR_TRANSPORT & 27 & 0.21 \\
\hline KEGG_APOPTOSIS & 64 & 0.20 \\
\hline KEGG_PPAR_SIGNALING_PATHWAY & 26 & 0.20 \\
\hline \multicolumn{3}{|l|}{ Day 1 down regulated } \\
\hline KEGG_RIBOSOME & 76 & 0.14 \\
\hline \multicolumn{3}{|l|}{ Day 2 enrichment } \\
\hline KEGG_RIG_I_LIKE_RECEPTOR_SIGNALING_PATHWAY & 40 & 0.00 \\
\hline KEGG_CYTOSOLIC_DNA_SENSING_PATHWAY & 31 & 0.00 \\
\hline KEGG_TOLL_LIKE_RECEPTOR_SIGNALING_PATHWAY & 69 & 0.00 \\
\hline KEGG_LYSOSOME & 88 & 0.02 \\
\hline KEGG_COMPLEMENT_AND_COAGULATION_CASCADES & 23 & 0.04 \\
\hline KEGG_PROTEASOME & 41 & 0.06 \\
\hline KEGG_CHEMOKINE_SIGNALING_PATHWAY & 103 & 0.08 \\
\hline KEGG_CYTOKINE_CYTOKINE_RECEPTOR_INTERACTION & 95 & 0.12 \\
\hline KEGG_NOD_LIKE_RECEPTOR_SIGNALING_PATHWAY & 37 & 0.15 \\
\hline KEGG_SNARE_INTERACTIONS_IN_VESICULAR_TRANSPORT & 27 & 0.15 \\
\hline KEGG_APOPTOSIS & 65 & 0.19 \\
\hline \multicolumn{3}{|l|}{ Day 2 down regulated } \\
\hline KEGG_RIBOSOME & 76 & 0.15 \\
\hline \multicolumn{3}{|l|}{ Day 7 enrichment } \\
\hline KEGG_RIG_I_LIKE_RECEPTOR_SIGNALING_PATHWAY & 39 & 0.00 \\
\hline KEGG_CYTOSOLIC_DNA_SENSING_PATHWAY & 30 & 0.00 \\
\hline KEGG_TOLL_LIKE_RECEPTOR_SIGNALING_PATHWAY & 66 & 0.09 \\
\hline KEGG_APOPTOSIS & 61 & 0.15 \\
\hline \multicolumn{3}{|l|}{ Day 7 down regulated } \\
\hline KEGG RIBOSOME & 76 & 0.20 \\
\hline \multicolumn{3}{|l|}{ Day 14 enrichment } \\
\hline KEGG_RIG_I_LIKE_RECEPTOR_SIGNALING_PATHWAY & 39 & 0.00 \\
\hline KEGG_CYTOSOLIC_DNA_SENSING_PATHWAY & 31 & 0.00 \\
\hline KEGG_TOLL_LIKE_RECEPTOR_SIGNALING_PATHWAY & 67 & 0.13 \\
\hline KEGG_COMPLEMENT_AND_COAGULATION_CASCADES & 21 & 0.18 \\
\hline KEGG_PROTEASOME & 41 & 0.22 \\
\hline \multicolumn{3}{|l|}{ Day 14 down regulated } \\
\hline KEGG_RIBOSOME & 76 & 0.18 \\
\hline \multicolumn{3}{|l|}{ Day 28 enrichment } \\
\hline KEGG_RIG_I_LIKE_RECEPTOR_SIGNALING_PATHWAY & 38 & 0.00 \\
\hline KEGG_CYTOSOLIC_DNA_SENSING_PATHWAY & 30 & 0.00 \\
\hline \multicolumn{3}{|l|}{ Day 28 down regulated } \\
\hline KEGG_RIBOSOME & 76 & 0.25 \\
\hline
\end{tabular}

Table 1 PBMC treated with IFN/ribavirin.

\begin{tabular}{lcl}
\hline Day 1 enrichment & \# of genes \\
\hline Pathway & $\begin{array}{c}\text { SIZE } \\
\text { FDR } \\
\text { q-val }\end{array}$ \\
\hline KEGG_CYTOSOLIC_DNA_SENSING_PATHWAY & 31 & 0.00 \\
\hline KEGG_RIG_ILLIKE_RECEPTOR_SIGNALING_PATHWAY & 40 & 0.00 \\
\hline
\end{tabular}

Table 2 List of ribosomal genes down regulated at day 1 and day 2 with fold difference.

\begin{tabular}{|c|c|c|}
\hline Ribosomal protein & Day 1 & Day 2 \\
\hline RPL10 & -1.67 & -1.45 \\
\hline RPL10 & -1.58 & -1.47 \\
\hline RPL10A & -1.60 & -1.52 \\
\hline RPL13 & -1.87 & -1.65 \\
\hline RPL13 & -1.75 & -1.57 \\
\hline RPL13 & -1.58 & -1.48 \\
\hline RPL13 & -1.49 & -1.46 \\
\hline RPL13 & -1.50 & -1.41 \\
\hline RPL13A & -1.53 & -1.41 \\
\hline RPL15 & -1.60 & -1.46 \\
\hline RPL18 & -1.61 & -1.51 \\
\hline RPL18A & -2.06 & -1.52 \\
\hline RPL22 & -1.79 & -1.63 \\
\hline RPL27AP & -1.68 & -1.44 \\
\hline RPL29 & -1.87 & -1.50 \\
\hline RPL29 & -1.71 & -1.45 \\
\hline RPL3 & -2.13 & -1.74 \\
\hline RPL3 & -1.62 & -1.53 \\
\hline RPL3 & -1.58 & -1.50 \\
\hline RPL3 & -1.57 & -1.46 \\
\hline RPL35 & -1.37 & -1.36 \\
\hline RPL35A & -1.58 & -1.37 \\
\hline RPL36 & -1.53 & -1.31 \\
\hline RPL4 & -1.78 & -1.72 \\
\hline RPL4 & -1.83 & -1.77 \\
\hline RPL4 & -1.61 & -1.56 \\
\hline RPL4 & -1.83 & -1.77 \\
\hline RPL6 & -1.42 & -1.35 \\
\hline RPL8 & -1.71 & -1.52 \\
\hline RPLPO & -1.89 & -1.65 \\
\hline RPLPO & -1.47 & -1.37 \\
\hline RPS10L & -1.53 & -1.48 \\
\hline RPS14 & -1.90 & -1.67 \\
\hline RPS16 & -1.57 & -1.48 \\
\hline RPS19 & -1.52 & -1.32 \\
\hline RPS19 & -1.45 & -1.30 \\
\hline RPS2 & -1.80 & -1.34 \\
\hline RPS2 & -1.60 & -1.43 \\
\hline
\end{tabular}


Table 2 List of ribosomal genes down regulated at day 1 and day $\mathbf{2}$ with fold difference. (Continued)

\begin{tabular}{lll}
\hline RPS28 & -1.69 & -1.54 \\
\hline RPS3 & -1.52 & -1.35 \\
\hline RPS5 & -2.02 & -1.82 \\
\hline RPS6 & -1.55 & -1.47 \\
\hline RPS6 & -1.41 & -1.38 \\
\hline RPS7 & -1.45 & -1.35 \\
\hline RPS8 & -1.56 & -1.55 \\
\hline RPS9 & -1.46 & -1.33 \\
\hline RPS9 & -1.47 & -1.37 \\
\hline
\end{tabular}

(average from 68 patients including non-responders

Figure 2 presents the enrichment data for ribosomal proteins and translation factors. A cluster at the top or bottom of the graph indicates significance. Unlike many other pathways, the suppression of ribosomal proteins and translation factors remains constant through out the treatment period. Although it is weaker at day 7, 14 etc., when much of the interferon/ribavirin effect has worn off.

\section{Discussion}

Treatment of HCV patients with pegylated interferon and ribavirin results in a suppression of expression of mRNA for ribosomal proteins and factors involved in protein synthesis, in PBMC isolated from patients. This

Table 3 Elongation and Initiation factors down regulated

\begin{tabular}{lll}
\hline Elongation factor & Day $\mathbf{1}$ & Day $\mathbf{2}$ \\
\hline EEF1B2 & -1.69 & -1.69 \\
\hline EEF1D & -1.67 & -1.53 \\
\hline EEF1G & -1.68 & -1.62 \\
\hline EEF1G & -1.68 & -1.61 \\
\hline EEF1G & -1.68 & -1.62 \\
\hline EEF2 & -1.95 & -1.76 \\
\hline EEF2 & -1.70 & -1.54 \\
\hline Initiation factor & & \\
\hline EIF2AK3 & -1.50 & -1.41 \\
\hline eIF3K & -1.30 & -1.29 \\
\hline eIF3K & -1.26 & -1.28 \\
\hline EIF3K & -1.18 & -1.21 \\
\hline EIF3S5 & -1.52 & -1.53 \\
\hline EIF3S6IP & -1.90 & -1.87 \\
\hline EIF3S7 & -1.38 & -1.38 \\
\hline EIF3S8 & -1.19 & -1.27 \\
\hline EIF4B & -2.20 & -1.97 \\
\hline EIF4B & -2.38 & -2.07 \\
\hline EIF4B & -1.58 & -1.42 \\
\hline EIF5B & -1.31 & -1.36 \\
\hline
\end{tabular}

suppression is global for ribosomal proteins and eukaryotic translation factors and persists through out the treatment period up to 28 days. The extent of down regulation is approximately $50 \%$.

We have previously reported the down regulation of a few individual ribosomal proteins and translation factors in PBMC in vitro and in vivo [5,9] following treatment with Interferon/ribavirin. In this paper we show that this is a global effect on the transcription of ribosomal protein genes. We have examined the effect of ribavirin alone on PBMC in vitro and find some decrease in mitochondrial ribosomal protein transcription but not on cytoplasmic ribosomal proteins (data not shown). Jiang et al. [11] reported the suppression of ribosomal protein L23 transcription during growth of a melanoma in culture treated with interferon alpha, beta and gamma but in the absence of ribavirin.

Meier et al. 2003 [12] reported the inhibition of DNA, RNA and protein synthesis in vitro on PBMC treated with PHA in the presence of high doses of ribavirin. This was a general effect and could be reversed by the addition of guanosine. A thorough analysis by Wadell et al. [13] shows a few ribosomal protein genes as being down regulated by IFN-beta and IFN-gamma in PBMC, although not by IFN-alpha. However the fold cut off used in these experiments as in our earlier experiments would not pick up the whole pathway. Thus it is likely that the combination of Interferon and ribavirin specifically affects transcription of the protein synthetic apparatus.

Unlike other genes affected by interferon/ribavirin treatment where we see transient changes in ISGs 6 days after interferon treatment, the down regulation of transcription of ribosomal proteins appears to be quite constant.

Interferon by itself has previously been shown to inhibit protein synthesis in a specific manner. This is through the dsRNA pathway in which RNAse $\mathrm{L}$ is activated and degrades viral RNA $[14,15]$. However it is unlikely that this down regulation of ribosomal protein gene mRNA is the result of non-specific RNA degradation since there is no effect over all in amounts of specific RNA in the cell as judged by the large number of genes (the majority) not affected by interferon/ribavirin treatment.

PKR an interferon induced (and activated) enzyme has been shown to phosphorylate eukaryotic initiation factor (EIF2) resulting in inhibition of viral protein synthesis [16]. Phosphorylation of eIF2 may have an effect on overall protein synthesis, however this is unlikely the case here since there is no evidence for general inhibition of protein synthesis. The expression of most genes is constant, and only a small percentage are either induced or suppressed. That viral protein synthesis in inhibited is shown by the decrease in viral titer during treatment in responding patients [5]. However the decrease in 


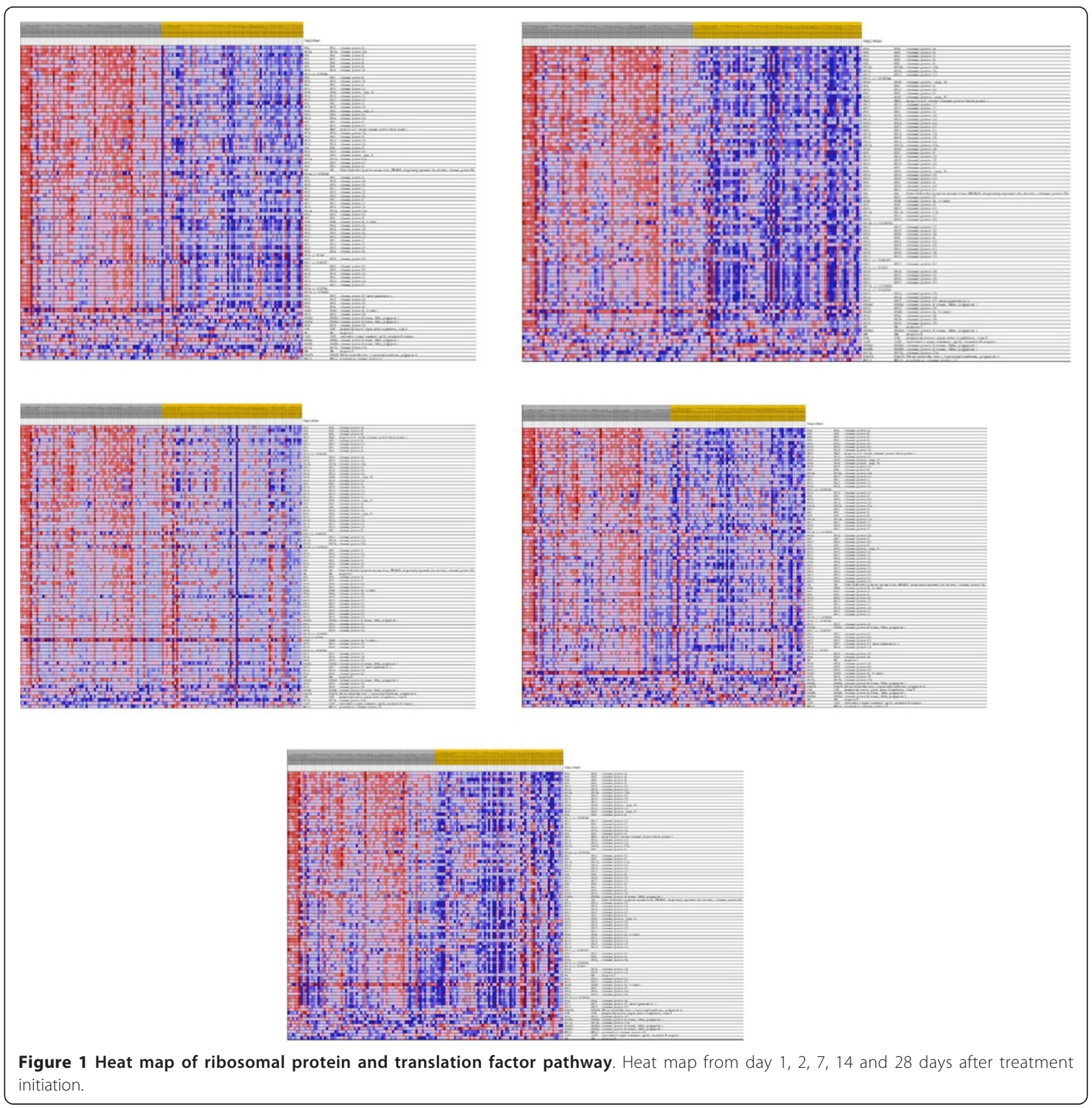

ribosomal protein gene transcription occurs even in nonresponding patients, although to a slightly lower level. This is in keeping with our previous data in which we have shown that in non-responsive patients there is a general blunting of the interferon/ribavirin effect [5].

MicroRNAs have been implicated in regulation of immune response in lymphocytes and in particular miRNA-146a has been shown to inhibit by a feed back mechanism the expression of interferon inducible genes. However a search of known microRNAs has not shown any relationship to ribosomal mRNA or Eukaryotic translation factors. It is possible that unknown microRNAs interact with common sequences in these genes and suppress transcription or degrade these RNAs. However this is purely speculative. We also were unable to find any common transcriptional regulatory sequence upstream of these genes. Previous reports [17-19] have indicated a possible role for $\mathrm{c}-\mathrm{myc}$ in regulating ribosomal protein transcription, however level of c-myc at the transcription level is unaffected by interferon/ribavirin in our analysis. It is likely that as cells slow down in growth, and undergo apoptosis that the rate of ribosomal protein 


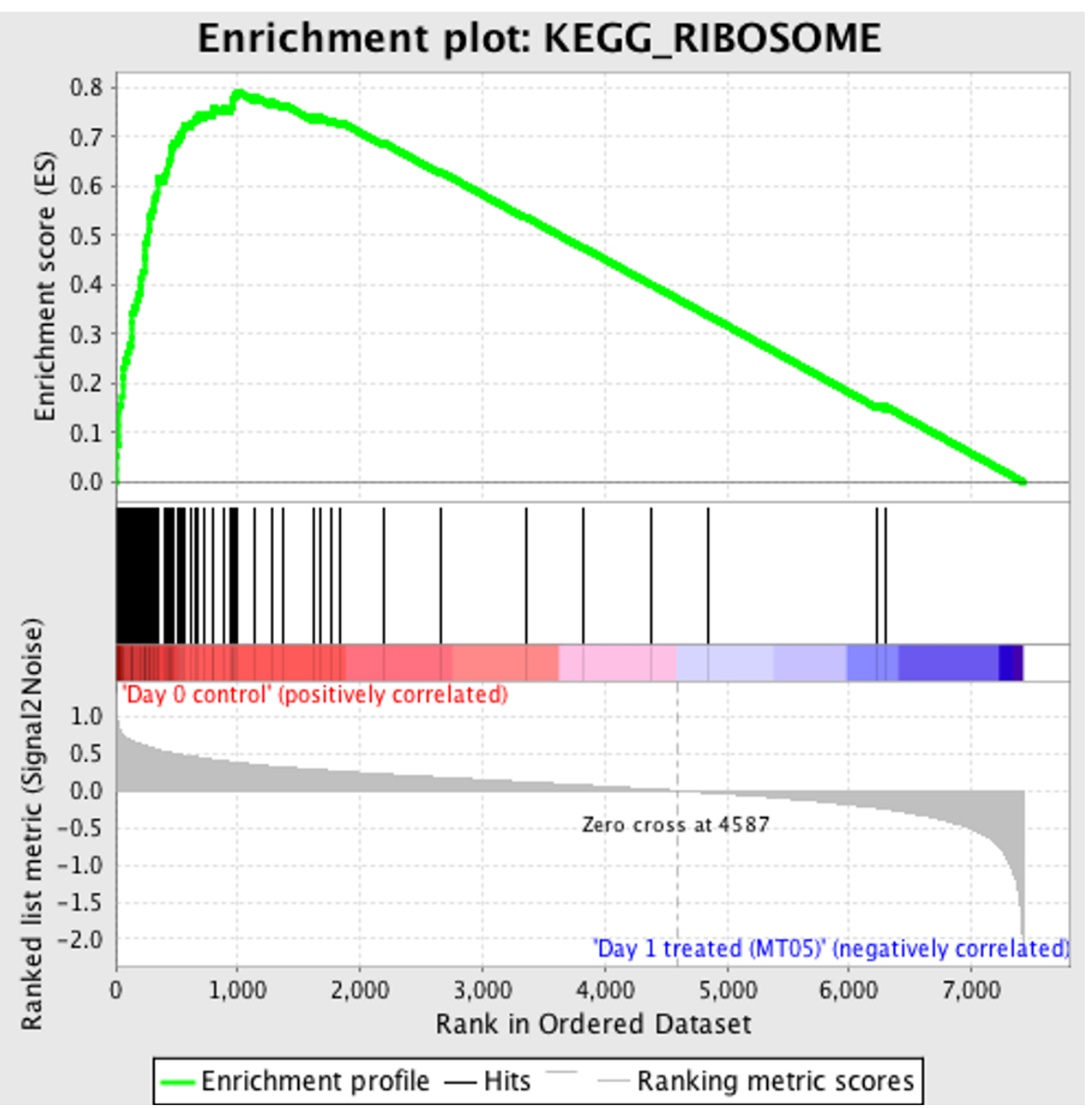

Figure 2 Enrichment plot of Ribosomal proteins and translation factors at day 1 after initiation of treatment.

and other proteins involved in translation will also decrease. We have previously noted (unpublished data) that myc transcription is significantly down regulated in a b-cell line, Daudi following treatment with interferonalpha. Thus the decrease reported here might reflect a decrease in ribosomal protein transcription in one class of immune cells.

The finding of a general decrease in the protein translation machinery would be an effective way of inhibiting virus. Viral load decrease often occurs in vivo a few days after the initial treatment with interferon/ribavirin. However this drug combination may also partially inhibit host protein synthesis in general, and lead to a variety of side effects in the patients. This could in part be an explanation for the flu like symptoms and anemia often seen in patients undergoing treatment with interferon/ribavirin. Whether this is due to interferon alone, or only occurs in the presence of ribavirin is not clear, although experiments in which PBMC were treated only with ribavirin did not show this effect on ribosomal proteins. However the levels used in these experiments may have been too low. This effect was not found in other cell lines treated with interferon in vitro and thus may be unique to PBMC [20] or to the combination treatment.

\section{Conclusions}

During treatment of hepatitis C patients with interferon/ ribavirin there is up regulation and down regulation of 
transcription of many genes. In this analysis we show that the genes for ribosomal proteins, and eukaryotic transcription and translation factors are down regulated at all time points measured (day 1,2,7,14, and 28). Down regulation of these genes has not been found in other cell types treated with interferon alone in vitro. We suggest that these data may explain in part the side effects often noted following interferon/ribavirin treatment as well as an early inhibition of viral replication.

\section{Acknowledgments}

This work was partially supported by Korea National Research Foundation 0543-20110016 to SK.

\section{Author details}

${ }^{1}$ School of Informatics and Computing, Indiana University, Bloomington, IN, USA. ${ }^{2}$ Department of Biology, Indiana University, Bloomington, IN, USA. ${ }^{3}$ Department of Computer Science and Engineering, Bioinformatics Institute, Interdisciplinary Program in Bioinformatics, Seoul National University, Seoul, Korea.

\section{Authors' contributions}

RG worked on this project towards a MS degree in informatics: MWT developed the data and helped with the analysis. KS helped with data analysis and statistics, and was mentor to RG. All authors read and approved the final manuscript.

\section{Competing interests}

The authors declare that they have no competing interests.

Received: 27 November 2011 Accepted: 22 March 2012

Published: 22 March 2012

\section{References}

1. Wong JB, McQuillan GM, McHutchison JG, Poynard T: Estimating future hepatitis C morbidity, mortality, and costs in the United States. Am J Public Health 2000, 90(10):1562-1569.

2. Sarrazin C, Rouzier R, Wagner F, Forestier N, Larrey D, Gupta SK, Hussain M, Shah A, Cutler D, Zhang J, et al: SCH 503034, a novel hepatitis C virus protease inhibitor, plus pegylated interferon alpha-2b for genotype 1 nonresponders. Gastroenterology 2007, 132(4):1270-1278.

3. Conjeevaram HS, Fried MW, Jeffers LJ, Terrault NA, Wiley-Lucas TE, Afdhal N, Brown RS, Belle SH, Hoofnagle JH, Kleiner DE, et al: Peginterferon and ribavirin treatment in African American and Caucasian American patients with hepatitis C genotype 1. Gastroenterology 2006, 131(2):470-477.

4. de Veer MJ, Holko M, Frevel M, Walker E, Der S, Paranjape JM, Silverman RH, Williams BR: Functional classification of interferon-stimulated genes identified using microarrays. J Leukoc Biol 2001, 69(6):912-920.

5. Taylor MW, Tsukahara T, Brodsky L, Schaley J, Sanda C, Stephens MJ, McClintick JN, Edenberg HJ, Li L, Tavis JE, et al: Changes in gene expression during pegylated interferon and ribavirin therapy of chronic hepatitis $C$ virus distinguish responders from nonresponders to antiviral therapy. J Virol 2007, 81(7):3391-3401.

6. Brodsky LI, Wahed AS, Li J, Tavis JE, Tsukahara T, Taylor MW: A novel unsupervised method to identify genes important in the anti-viral response: application to interferon/ribavirin in hepatitis C patients. PLOS One 2007, 2(7):e584.

7. Skov V, Glintborg D, Knudsen S, Jensen T, Kruse TA, Tan Q, Brusgaard K, Beck-Nielsen H, Hojlund K: Reduced expression of nuclear-encoded genes involved in mitochondrial oxidative metabolism in skeletal muscle of insulin-resistant women with polycystic ovary syndrome. Diabetes 2007, 56(9):2349-2355.

8. Taylor MW, Tsukahara T, McClintick JN, Edenberg HJ, Kwo P: Cyclic changes in gene expression induced by Peg-interferon alfa-2b plus ribavirin in peripheral blood monocytes (PBMC) of hepatitis $\mathrm{C}$ patients during the first 10 weeks of treatment. J Transl Med 2008, 6:66.
9. Taylor MW, Grosse WM, Schaley JE, Sanda C, Wu X, Chien SC, Smith F, Wu TG, Stephens M, Ferris MW, et al: Global effect of PEG-IFN-alpha and ribavirin on gene expression in PBMC in vitro. J Interferon Cytokine Res 2004, 24(2):107-118.

10. Subramanian A, Tamayo P, Mootha VK, Mukherjee S, Ebert BL, Gillette MA, Paulovich A, Pomeroy SL, Golub TR, Lander ES, et al: Gene set enrichment analysis: a knowledge-based approach for interpreting genome-wide expression profiles. Proc Natl Acad Sci USA 2005, 102(43):15545-15550.

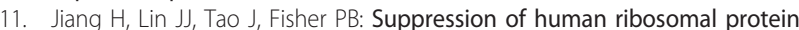
L23A expression during cell growth inhibition by interferon-beta. Oncogene 1997, 14(4):473-480.

12. Meier V, Burger E, Mihm S, Saile B, Ramadori G: Ribavirin inhibits DNA, RNA, and protein synthesis in PHA-stimulated human peripheral blood mononuclear cells: possible explanation for therapeutic efficacy in patients with chronic HCV infection. J Med Virol 2003, 69(1):50-58.

13. Waddell SJ, Popper SJ, Rubins KH, Griffiths MJ, Brown PO, Levin M, Relman DA: Dissecting interferon-induced transcriptional programs in human peripheral blood cells. PLoS One 2010, 5(3):e9753.

14. Silverman RH, Dong B, Maitra RK, Player MR, Torrence PF: Selective RNA cleavage by isolated RNase $L$ activated with 2-5A antisense chimeric oligonucleotides. Methods Enzymol 2000, 313:522-533.

15. Zhou A, Paranjape JM, Hassel BA, Nie H, Shah S, Galinski B, Silverman RH: Impact of RNase $L$ overexpression on viral and cellular growth and death. J Interferon Cytokine Res 1998, 18(11):953-961.

16. Thomis DC, Samuel CE: Mechanism of interferon action: evidence for intermolecular autophosphorylation and autoactivation of the interferon-induced, RNA-dependent protein kinase PKR. J Virol 1993, 67(12):7695-7700.

17. Lempiainen $H$, Shore D: Growth control and ribosome biogenesis. Curr Opin Cell Biol 2009, 21(6):855-863.

18. Boon $K$, Caron HN, van Asperen $R$, Valentijn $L$, Hermus MC, van Sluis $P$, Roobeek I, Weis I, Voute PA, Schwab M, et al: N-myc enhances the expression of a large set of genes functioning in ribosome biogenesis and protein synthesis. EMBO J 2001, 20(6):1383-1393.

19. Lindstrom MS: Emerging functions of ribosomal proteins in gene-specific transcription and translation. Biochem Biophys Res Commun 2009, 379(2):167-170.

20. Sanda C, Weitzel P, Tsukahara T, Schaley J, Edenberg HJ, Stephens MA, McClintick JN, Blatt LM, Li L, Brodsky L, et al: Differential gene induction by type I and type II interferons and their combination. J Interferon Cytokine Res 2006, 26(7):462-472.

doi:10.1186/1479-5876-10-54

Cite this article as: Gupta et al:: Suppression of ribosomal protein synthesis and protein translation factors by Peg-interferon alpha/ ribavirin in HCV patients blood mononuclear cells (PBMC). Journal of Translational Medicine 2012 10:54.

\section{Submit your next manuscript to BioMed Central and take full advantage of:}

- Convenient online submission

- Thorough peer review

- No space constraints or color figure charges

- Immediate publication on acceptance

- Inclusion in PubMed, CAS, Scopus and Google Scholar

- Research which is freely available for redistribution

Submit your manuscript at www.biomedcentral com/submit
C) Biomed Central 